\title{
PENERAPAN STRATEGI PEMASARAN SEBAGAI UPAYA MENINGKATKAN USAHA KECIL DAN MENENGAH WARGA DI DESA CICALENGKA KECAMATAN PAGEDANGAN KABUPATEN TANGERANG-BANTEN
}

\author{
Prasetyo Kurniawan, Suwanto, Priehadi Dhasa Eka, Angga Juanda, \\ Muhammad Gandung \\ Universitas Pamulang \\ Email: dosen02261@unpam.ac.id
}

\begin{abstract}
The purpose of carrying out this community service is to assist business actors in promoting UKM products in Cicalengka Village, Pagedangan District, Tangerang-Banten Regency. This method of community service activities begins with the preparation stage and field surveys. This survey phase begins with direct discussions with the board of directors and village officials in Pagedangan-Banten District to identify the needs, opportunities and challenges faced by UKM entrepreneurs. Then, the socialization and training stage was carried out by the team. At this stage there are five things that are carried out by the service team, namely (1) how to make attractive products, (2) looking for strategic locations (3) doing and practicing promotional content that is easy on social media (4). And how to distribute the product so that it reaches the customer. (5). Online marketing. The output target to be achieved in this community service activity is that UKM in Cicalengka Village, Pagedangan District, especially home-based entrepreneurs, have an entrepreneurial spirit capable of managing good business management and marketing strategies. Dedication articles published in the most accredited Journal. Articles published in the mass media / national newspapers.
\end{abstract}

Keywords: Marketing strategy, UKM.

\begin{abstract}
Abstrak
Tujuan dilaksanakannya pengabdian kepada masyarakat ini adalah untuk membantu para pelaku usaha dalam mempromosikan produk UKM di Desa Cicalengka Kecamatan Pagedangan Kabupaten Tangerang-Banten. Metode kegiatan pengabdian kepada masyarakat ini dimulai dengan tahap persiapan dan survei lapangan. Tahap survei ini dimulai dengan berdiskusi langsung bersama jajaran pengurus dan perangkat desa Kecamatan Pagedangan-Banten untuk mengidentifikasi kebutuhan, peluang, dan tantangan yang dihadapi oleh para pelaku usaha UKM. Kemudian, tahap sosialisasi dan pelatihan dilakukan oleh tim. Pada tahap ini ada lima hal yang dilaksanakan oleh tim pengabdi, yaitu (1) bagaimana cara membuat produk yang menarik, (2) mencari lokasi yang strategis (3) melakukan dan praktek konten promosi yang mudah di medsos (4). Dan bagaimana cara mendistribusikan produk sehingga bisa sampai ke pelanggan. (5). Pemasaran online. Target luaran yang akan dicapai
\end{abstract}


dalam kegiatan pengabdian masyarakat ini pelaku UKM di Desa Cicalengka Kecamatan Pagedangan khususnya pelaku usaha rumahan agar memiliki jiwa wirausaha (entrepreneur) yang mampu mengelola manajemen usaha dan strategi pemasaran yang baik. Artikel pengabdian yang dipublikasikan di Jurnal terakredatis. Artikel termuat di media massa / Surat kabar nasional.

Kata Kunci: Strategi Pemasaran, UKM.

\section{A. PENDAHULUAN}

UMKM merupakan sektor usaha yang memiliki peran penting terhadap perekonomian nasional. UMKM adalah penopang perekonomian suatu negara dalam menghadapi berbagai krisis. Dalam krisis ekonomi yang terjadi di Indonesia pada tahun 1998 yang lalu, banyak usaha berskala besar yang mengalami kebangkrutan, akan tetapi sektor UMKM terbukti tangguh dan memiliki daya tahan yang kuat dalam menghadapi krisis tersebut. Usaha Kecil Menengah (UKM) adalah salah satu sektor ekonomi yang sangat kontribusi terhadap perekonomian Indonesia. UKM mempunyai peran yang strategis dalam pembangunan ekonomi nasional. Hal ini terlihat dari kontribusinya terhadap Produk Domestik Bruto (PDB) Indonesia yang meningkat setiap tahunnya. Dalam krisis ekonomi yang terjadi di Indonesia sejak beberapa waktu yang lalu, dimana banyak usaha berskala besar mengalami stagnasi bahkan berhenti aktifitasnya, sektor UKM terbukti lebih tangguh dalam menghadapi krisis tersebut. Sumber daya manusia sendiri adalah seluruh kemampuan atau potensi penduduk yang berada di dalam suatu wilayah tertentu beserta karakteristik atau ciri demografis, sosial maupun ekonominya yang dapat dimanfaatkan untuk keperluan pembangunan. Jadi membahas sumber daya manusia berarti membahas penduduk dengan segala potensi atau kemampuannya. Potensi manusia menyangkut dua aspek yaitu aspek kuantitas dan kualitas.

Alasan-alasan UKM bisa bertahan dan cenderung meningkat jumlahnya pada masa krisis adalah yang Pertama sebagian besar UKM memproduksi barang konsumsi dan jasajasa dengan elastitas permintaan terhadap pendapatan yang rendah. Kedua sebagian besar UKM tidak mendapatkan modal dari bank. Ketiga UKM mempunyai modal yang terbatas dan pasar yang bersaing. Keempat reformasi menghapuskan hambatan-hambatan di pasar, proteksi industri dihilangkan, UKM mempunyai pilihan lebih banyak dalam pengadaan bahan baku, akibatnya biaya produksi turun dan efisiensi meningkat. Kelima dengan adanya krisis ekonomi yang berkepanjangan menyebabkan sektor formal banyak menghentikan pekerja-pekerjanya, para penganggur tersebut melakukan kegiatan usaha yang umumnya berskala kecil yang mengakibatkan jumlah UKM meningkat, (Pratomo dan Soejoedono, 2004:24). Untuk itu pembangunan ekonomi rakyat seharusnya menjadi prioritas utama pembangunan ekonomi nasional, karena tujuan pembangunan ekonomi rakyat sesuai dengan amanat konstitusi yaitu: meningkatkan kesejahteraan dan keadilan sosial bagi seluruh rakyat Indonesia. Reformasi dalam sistem ekonomi nasional harus diarahkan kepada sistem ekonomi kerakyatan yang memberikan prioritas pembangunan ekonomi pada Koperasi dan Usaha Mikro, Kecil dan Menengah. Diakui bahwa usaha mikro kecil dan menengah (UMKM) memainkan peran penting di dalam pembangunan dan pertumbuhan ekonomi, tidak hanya di negara-negara sedang berkembang, tetapi juga dinegara-negara maju. Di negara maju UMKM sangat penting, tidak hanya karena kelompok usahanya tersebut menyerap paling banyak tenaga kerja dibandingkan usaha besar, tetapi juga kontribusinya terhadap pembentukan dan pertumbuhan produk domestik bruto (PDB) paling besar dibandingkan kontribusinya dari usaha besar. 


\section{B. METODE PELAKSANAAN}

Pelaksanaan kegiatan pengabdian berlangsung pada tanggal 27 - 29 Maret 2021, dengan dihadiri 22 (dua puluh dua) warga Desa Cicalengka Kecamatan Pagedangan. Ada beberapa metode pendekatan yang digunakan dalam pelaksanaan program, meliputi sebagai berikut:

1. Sosalisasi

Program pengabdian kepada masyarakat dilaksanakan dalam bentuk sosialisasi kepada warga di Desa Cicalengka Kecamatan Pagedangan. Sosialisasi tersebut berupa pemamparan materi kepada mitra terkait permasalahan yang dihadapi.

2. Diskusi

Setelah materi selesai dipaparkan, dilanjutkan dengan diskusi berupa tanya jawab antara pemateri dengan peserta. Diskusi dilakukan agar peserta lebih memahami materi yang telah disampaikan.

3. Praktek

Praktek membuat iklan dan promosi di media social dengan menarik. Pada pelatihan pembuatan iklan dan promosi, kita memvideokan cara pembuatannya dan menampilkan video tersebut pada saat praktek pembuatan, sehingga bisa menambah pengetahuan dengan kemajuan teknologi saat ini.

\section{HASIL DAN PEMBAHASAN}

Pelaksanaan pelatihan penerapan strategi pemasaran sebagai upaya menigkatkan UKM secara sederhana bagi Warga Desa Cicalengka Kecamatan Pagedangan Kabupaten Tangerang, dilaksanakan pada tanggal 27-28 Maret 2021 bertempat di kantor Desa Cicalengka RT 002/RW 002 Kecamatan Pagedangan. Acara pertama diawali dengan Sambutan kepala Desa Cicalengka sekaligus mengisi tanya jawab seputar penerapan stretegi pemasaran untuk UKM yang di isi oleh tim Dosen Universitas Pamulang.

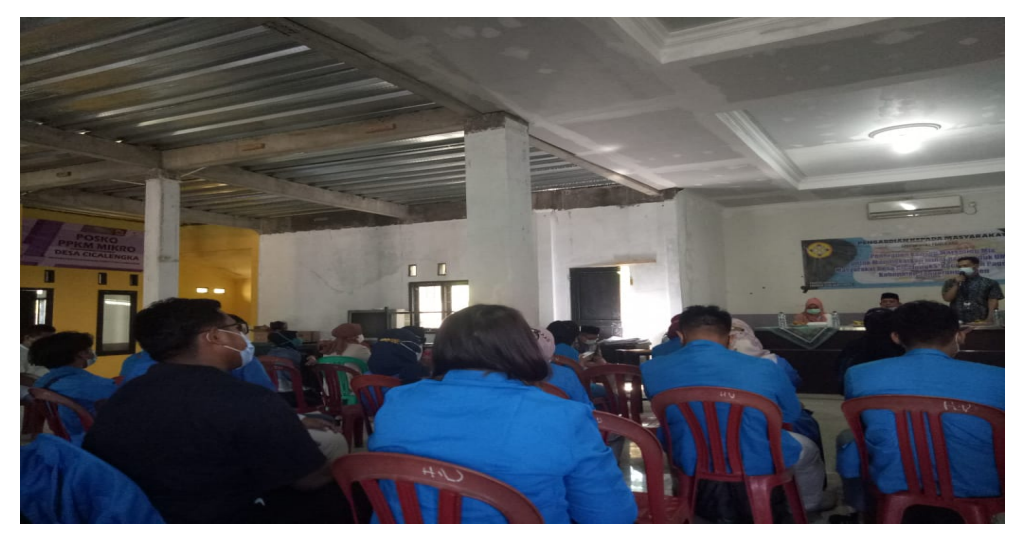

Gambar 1. Penyampaian Materi Oleh Tim PKM

Acara selanjutnya, Ada beberapa metode pendekatan yang digunakan dalam pelaksanaan program PKM Dosen, meliputi :

1. Sosalisasi, Program pengabdian kepada masyarakat dilaksanakan dalam bentuk sosialisasi kepada mitra pelaku usaha UKM di Desa Cicalengka Kecamatan Pagedangan. Sosialisasi tersebut berupa pemamparan materi kepada mitra terkait permasalahan yang dihadapi mitra. Materi yang akan disampaikan diharapkan dapat memberikan peningkatan pengetahuan dan pemahaman untuk selanjutnya dapat diterapkan oleh mitra dalam kegiatan usaha. 
2. Diskusi, Setelah materi selesai dipaparkan, dilanjutkan dengan diskusi berupa tanya jawab antara pemateri dengan peserta. Diskusi dilakukan agar peserta lebih memahami materi yang telah disampaikan. Melalui diskusi, sosialisasi tidak hanya sekedar transfer knowledge saja melainkan dapat sharing pengalaman maupun permasalahan yang sedang dihadapi mitra.

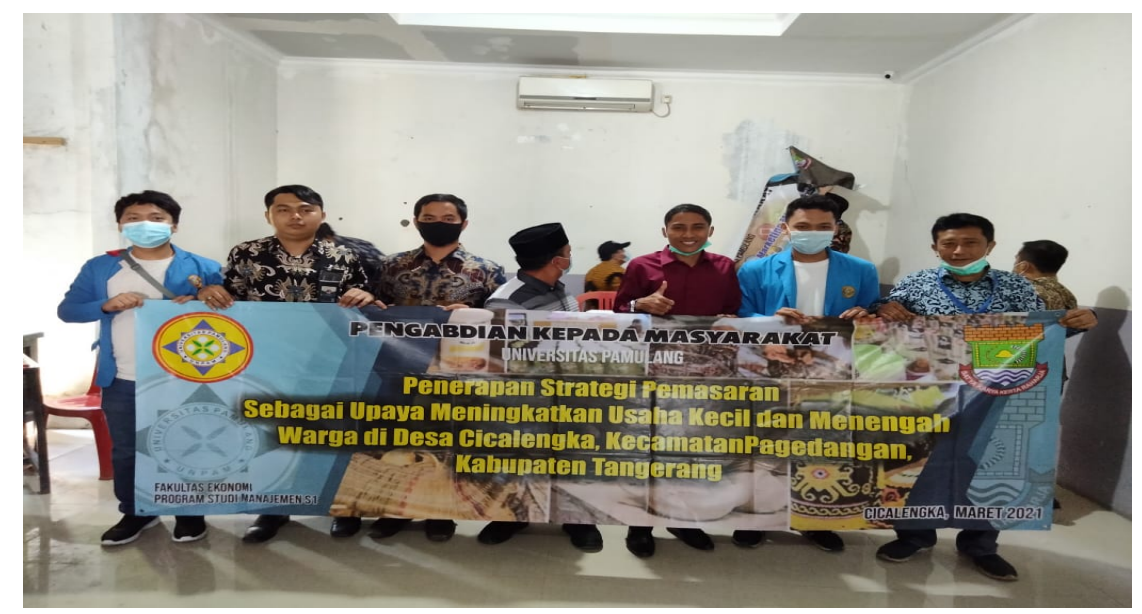

Gambar 2. Foto bersama Kepala Desa dan Warga

Di sela-sela penyampaian materi, pemateri mengadakan interaksi secara langsung dengan peserta, yakni menanyakan usaha apakah yang kira-kira akan mereka jalani jika akan membuka usaha. Peserta terlihat antusias. Setelah materi selesai disampaikan, diadakan selingan untuk menghibur para peserta sebelum melanjutkan materi berikutnya. Tim menampilkan tayangan berupa video yang berhubungan dengan materi perencanaan usaha untuk melihat respon peserta. Kemudian menjelaskan juga bagaiana mendistribusikan barang ini merupakan salah satu jantung dalam berbisnis.

\section{KESIMPULAN DAN SARAN}

\section{Kesimpulan}

Kegiatan Pengetahuan peserta dalam hal ini warga di Desa Cicalengka Kecamatan Pagedangan Kabupaten Tangerang-Banten mengenai strategi pemasaran sebelum kegiatan PKM mayoritas berada di kategori kurang memahami. Setelah kegiatan PKM dilaksanakan dan pemaparan materi disampaikan, diketahui bahwa pengetahuan peserta mengenai strategi pemasaran setelah disampaikan semakin meningkat dan termotivasi untuk meningkatkan usahanya.

\section{Saran}

Diharapkan dengan adanya pengabdian kepada masyarakat ini dapat membuka wawasan dari masyarakat khususnya pelaku UKM di Desa Cicalengka Kecamatan Pagedangan Kabupaten Tangerang-Banten untuk dapat menerapkan strategi pemasaran yang efektif dan inovatif sehingga mampu bersaing dengan produk-produk di dalam negeri maupun dari luar negeri. 


\section{DAFTAR PUSTAKA}

Alma. B. (2015), Manajemen Pemasaran dan Pemasaran Jasa, Bandung: Alfabeta

Cummins. J. (2014), Sales Promotion, Jakarta: PPM

Beik, I. S., dan Arsyanti. L. D. (2016), Ekonomi Pembangunan Syariah, Jakarta: Rajawali Pers.

Kotler. P., \& Amstrong. G. (2016), Prinsip-prinsip Pemasaran. Edisi 13. Jilid 1, Jakarta: Erlangga.

Kotler. P., \& Keller. K. L. (2016), Prinsip-Prinsip Pemasaran. Edisi13. Jilid 1. Jakarta: Erlangga.

Mullins, J. W., \& Walker J. O. C. (2013). Marketing Management: A Strategic DecisionMaking Approach, 8th Edition, McGraw-Hill International Edition.

Pratomo T. S, Soejoedono A. R. (2002). Ekonomi Skala Kecil/Menengah dan Koperasi. Jakarta: Ghalia Indonesia.

Rangkuti. F. (2014). Analisis SWOT: Teknik Membedah Kasus Bisnis. Jakarta. PT Gramedia Pustaka Utama.

Solihin, D., Susanto, N., Setiawan, R., Ahyani, \& Darmadi. (2020). Penerapan Strategi Pemasaran Sebagai Upaya Meningkatkan Usaha Kecil Dan Menengah Warga Di Kelurahan Paninggilan Utara Ciledug. ABDI LAKSANA, 1(3), 351-355.

Solihin, D., Prasetiyani, D., Sari, A. R., Sugiarti, E., \& Sunardi, D. (2020). Pemanfaatan Botol Bekas Sebagai Penyaring Air Bersih Sederhana Bagi Warga Desa Cicalengka Kecamatan Pagedangan Kabupaten Tangerang. DEDIKASI PKM, 1(3), 98-102.

Solihin, D. (2020), Faktor-Faktor Yang Mempengaruhi Kinerja Pemasaran Pada PT Prima Ufuk Semesta (Studi Empiris Pada Outlet Rekanan PT. Prima Ufuk Semesta di Wilayah JABODETABEK), Jurnal Semarak. 3(1).

Solihin, D. (2020), Pengaruh Kepercayaan Pelanggan Dan Promosi Terhadap Keputusan Pembelian Konsumen Pada Online Shop Mikaylaku Dengan Minat Beli Sebagai Variabel Intervening. Jurnal Mandiri: Ilmu Pengetahuan, Seni, dan Teknologi 4(1).

Solihin, D., \& Wibawanto, E. (2020). Pengaruh Kualitas Pelayanan, Harga, Dan Promosi Terhadap Keputusan Pelanggan Dalam Memilih Klub Basket Satria Indonesia Tangerang Selatan. Jurnal Pemasaran Kompetitif. 3(3).

Solihin, D. (2019), Pengaruh Current Ratio dan Debt To Equity Ratio Terhadap Return On Asset (ROA) Pada PT Kalbe Farma, Tbk. KREATIF: Jurnal Ilmiah Prodi Manajemen Universitas Pamulang. 7 (1), 115-122.

Sudaryono, (2016), Manajemen Pemasaran: Teori dan Implementasi, Yogyakarta: Penerbit Andi.

Stanton, W. J. (2012). Prinsip Pemasaran, Alih Bahasa: Yohanes Lamarto. Jakarta: Penerbit Erlangga.

Swastha. B. (2012), Manajemen Penjualan, Edisi 3, Yogyakarta, BPFE.

Tjiptono. F. (2014), Pemasaran Jasa, Yogyakarta, Andi. 